\title{
AN OVERVIEW ON THE STUDIES ABOUT ORGANIZATIONAL CULTURE IN JOURNALS IN THE BUSINESS ADMINISTRATION AREA (2008-2013)
}

\section{Andrieli Diniz Vizzoto}

Masters Student in Administration at the Federal University of Santa Maria, Brazil avizzoto@gmail.com

\section{Breno Augusto Diniz Pereira}

Doctorate degree in Administration at Federal University of Santa Maria, Brazil Associate Professor at the Administrative Sciences Department and Coordinator of the Postgraduate program in Administration, Federal University of Santa

Maria, Brazil

brenodpereira@gmail.com

\section{Marina Ferraz Campanher}

Baccalaureate degree in psychologist at the Federal University of Santa Maria, Brazil

marinacampanher@gmail.com

\section{Felipe da Silva Ravanello}

Baccalaureate student in Administration at the Federal University of Santa Maria, Brazil

feliperavas@gmail.com

\section{ABSTRACT}

The literature, specially in the areas of Administration, Psychology and Sociology, has paid attention to the values as guides of human and organizational behavior in private and public companies. This study has aimed to present how the organizational culture has been studied through a review of scientific journals that have published articles on the subject, comprising the years from 2008 to 2013 and making a comparison between the reality of Brazilian and international publications. Seeking to provide some perspective on the current scenario in the theme, this article is characterized as a bibliometric study. A research for some specific words was conducted. Some Brazilian and international articles found were analyzed separately to keep the keywords as chosen by the authors, as a way to compare Brazilian publications with international ones. Some authors notice the need for studies comprising the understanding of how organizational culture is 

TRENDS AND STRATEGIES

\section{Profuturo: Future Studies Program}

Scientific Editor: James Terence Coulter Wright Evaluation: Double Blind Review, by SEER/OJS

Review: Grammatical, Normative and layout

Received on:11/21/2013. Approved on:01/23/2014

perceived by the literature and how are being held the studies in this area. 522 articles were found in international databases and 31 in Brazilian journals that were in accordance with the limits of this research. The study shows some differences between Brazilian and international publishings and how there is still room for more studies linking organizational culture and other subjects in the field of Administration.

Key-words: Organizational culture. Brazilian articles. International articles. Scientific journals. 


\section{INTRODUCTION}

Over time, questions about the organizational diversities have permeated different areas of knowledge, such as Anthropology, Psychology and Sociology. In Business Administration, the interaction of the intrinsic elements that lead to the construction of social reality has been analyzed from the point of view of organizational culture, among others, requiring an understanding of the set of organizational values and other elements of everyday in business (Motta, 1998).

Important parts of human behavior are shaped by culture, values, and individual and organizational beliefs that guide individuals and the organizations' behavior adopted to face the challenges. The literature, specially in the areas of Administration, Psychology and Sociology, has paid attention to the values as guides of human and organizational behavior in private and public companies (Motta \& Vasconcelos, 2004).

Nevertheless, there is still little understanding of how organizational culture actually works (Alvesson, 2002), and according to the importance this issue has in organizations, there is the need of developing theories in this field of study, which can and should come from several areas, enriching the knowledge on it, such as Administration, Anthropology, Psychology, etc.

As in Coelho Junior (2003) culture is an important factor when analyzing the character of an organization, it is a process of social interactions, present in the the successes and failures of each company, which defines the language that is imbued with the goals, visions and objectives.

However, the concept of organizational culture is very diverse in the literature, there is no single well-delimited definition, making the studies that consider the cultural aspect of the organization different in their definitions and methodology (Coelho Junior \& Borges-Andrade, 2004).

In this sense, this study has aimed to present how the organizational culture has been studied through a review of the major scientific journals that have published articles on the subject, comprising the years from 2008 to 2013 and making a comparison between the reality of Brazilian and international publications. 


\section{ORGANIZATIONAL CULTURE}

Organizational culture can be described as a set of beliefs, behaviors, artifacts, symbols, practices and values. According to Schein (2004) organizational culture is the combination of these with the beliefs of the organization members about appropriate behaviors. Thus, culture involves beliefs and behaviors, existing at various levels to the deepest ones of the organization, and it is present in all the features of organizational life (Hofstede, 2001).

As for Engman and Thörnlund (2008) the culture of an organization should be adopted by employees, because it influences the daily activities at work, and the culture is what motivates the company's work. Also, the managers of organizations are primarily responsible for creating and maintaining a organizational culture as a group effort.

The organizational culture is made by both the identities of the employees and the collective identity of these and the corporate identity (Fuhse \& Mützel, 2011). Thus, organizational culture is a combination of artifacts, values, beliefs that are recognized by members of the organization and coordinate which are the acceptable behaviors at work.

In Schein (2004) there is the definition of organizational culture as a three level structure that create the totality, but can be seen, lived and studied separately.

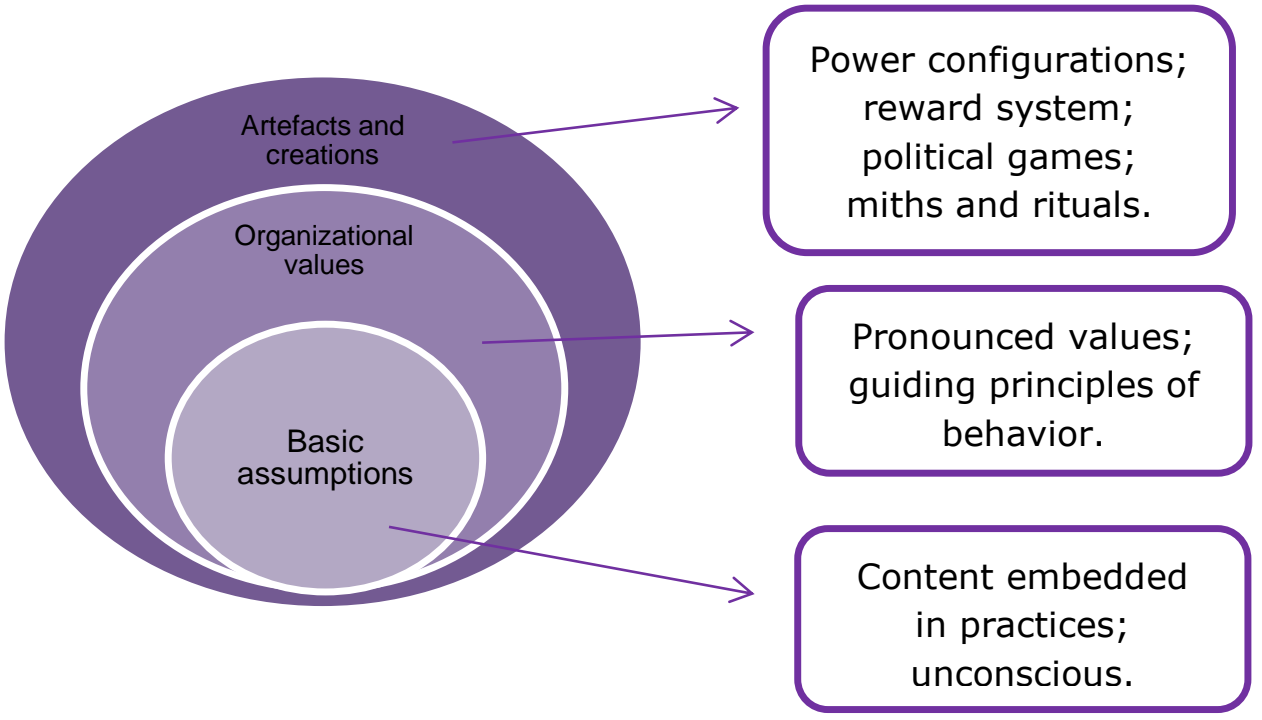

Figure 1: Levels of the organizational culture

Source: Based on Schein (2004) 
According to Schein's point of view (2004) the organizational culture has three levels which can be analized and which are lived by the organization and its members.

The artifacts and creations are the most external level of culture, and it is the surface and more visible part, composing the power settings of the organization, organizational structure, system and criteria for reward, and the political and change and power games, and myths, rituals and stories that convey what the organization expects of its employees, strengthening the rules informally.

After that, the organizational values are at a deeper level, being manifested by the organization and its members, and having three axes of understanding: autonomy-preservation; domain-hierarchy, and harmonydomain. The first axis considers the relation of the individual, who must have autonomy to their actions within the group, which needs conservation so that the rules are always clear and to create a culture of trust for stability. The second axis considers the structure as vertical and reigning over the individual or as horizontal, which privileges the group. Finally, the third axis considers the environment which needs to be harmonious with the organization, and also the domain is needed to make the necessary changes for the organization survival.

Lastly, the basic assumptions are the innermost level of culture, the foundation of the organization and that are allocated in it deeply, deep certainties that are unaware on individuals and regulate their behavior within the organization in an unnoticed way.

In Vieira (2010) it is possible to find that the elements which constitute the culture must be present in everyone's memory, because it is through them that members rely to act and legitimate organizational practices. Only in this way the organization can be a reference to the behaviors and imposes its own standards and thus making members experience the organizational culture.

\section{ORGANIZATIONAL CULTURE: SCENE OF THE CURRENT STUDIES}

Some authors notice the need for studies comprising the understanding of how organizational culture is perceived by the literature and how are being held the studies in this area (Plakhotnik \& Rocco, 2006; Coelho Junior \& Borges- 
Andrade, 2004; Pereira, Passos \& Carvalho, 2010). So, some studies have been conducted seeking to understand the researches in the area, through searches on the theme. Some of these studies are listed below:

- In Plakhotnik and Rocco (2006) it was conducted a literature review in Human Resources from 1994 to 2005. The authors searched for production in the scientific areas such as Administration, Psychology, Organizational Behavior and others in order to understand how organizational culture had been studied by researchers and how it was defined. Information was sought in the titles, abstracts, keywords, research problem and objectives in articles that contained the terms "culture, organizational". According to the authors, 1510 publications were found, of which 31 were chosen in a way that is not explicit, to have their contents examined.

When reviewing the articles, Plakhotnik and Rocco (2006) found that 23 of them had culture defined in terms as: shared values, assumptions and behaviors, the context of dominance, business orientation, learning and human culture. Also studies can be divided into relational (linking culture to other internal or external factors) or exploratory (examining the phenomenon of organizational culture). The authors also assume that the low number of articles shows a lack of publications in the area of organizational culture, showing disinterest, which is a worrying fact, since organizational culture is one of the central issues in the practice of business management. Moreover, existing studies are focused on a rational perspective, which makes room for the need of many studies that broaden the horizons in understanding the organizational culture (Plakhotnik \& Rocco, 2006).

- In Coelho Junior and Borges-Andrade (2004), it was realized an empirical analysis of the Brazilian production on organizational culture. The research has aimed at reviewing the main Brazilian scientific journals in the areas of Administration and Psychology from 1996 to 2001. The authors believe that the literature provides a variety of organizational culture concepts and this provides a variety of studies, since the focus may be changed in accordance with the understanding that the authors use for culture.

This study selected periodicals that were highly satisfactory in accordance with the criteria of Capes (Coordination of Improvement of Higher Education 
Personnel) and were only accepted articles with empirical research. The results discussed show that the findings may indicate that the subject organizational culture should be further addressed, it has a theoretical background very incipient. And the authors suggest that further studies should be made not only focusing on case studies of specific organizations, which seems to be the focus of studies in the area, but seeking comparative studies with validation of instruments or validation or refutation of hypotheses.

- In the study by Pereira, Passos and Carvalho (2010) some articles containing as keywords "organizational culture" were selected, from the basis of national journals in Administration SciELO from 1998 to 2009. The authors sought to map the publications on this theme and identify the most commonly used references. They analyzed the journal, keywords, authors, educational institutions, references and the year. 27 articles were found, concentrated in five magazines. Besides the low number of articles and journals, the authors of those articles also demonstrated to be concentrated as well as the institutions to which the authors are associated.

It was also identified the themes which were related to organizational culture, and some connections were found as organizational change, organizational identity, commitment, learning and others. The results were limited by the numbers of publishings, and Pereira, Passos and Carvalho (2010) suggest that it is necessary to expand the study to other periodicals and even some events in the Business area.

- Also, there is the study of Vieira and Fischer (2005), which proposes an analysis of scientific literature on the topics of climate, culture and salaries, covering a period from 1990 to 2004. The authors made a theoretical review of the topics addressed in national journals and sought the journals which had easy and free access to articles, dissertations and theses that contained in the keywords, summary or title the words "organizational climate", "organizational culture", "compensation" and "salary".

With a total of 146 articles found, they had an average of 9.66 articles per year on the topics analyzed and as the main result a sample denoting a remarkable growth of scientific production in human resources from year to year, 
demonstrating that studies have gained ground and importance in the area (Vieira \& Fischer, 2005).

- And also trying to understand the scientific literature on organizational culture, there is the study of Silva and Fadul (2010), covering the period from 1997 to 2007, aiming mainly to focus on organizational culture in public organizations. The study sought outcomes in Brazilian scientific journals and meetings sponsored by Anpad (National Association of Post Graduate Studies and Research in Administration). The authors conclude that it is a useful field, but it requires new perspectives and ways of understanding the reality of Brazilian public organizations, as the studies - though few - always focus on the immutability of the organizational culture of the public sector in Brazil.

- Finally, in Heinzmann, Machado and Ropelato (2010) the study was made to understand the social networks formed by the authors of the national Brazilian literature on organizational culture, to comprehend also how widespread is the knowledge about the topic. The study analyzed the records of ANPAD events and national journals in the area of administration with classification $A$ and $B$ in qualis Capes. The research considered the period from 1998 to 2009, selecting only items containing in the title, abstract or keywords at least one of the terms "organizational culture", "corporate culture", "culture in organizations" and "culture of organizations."

So, 195 articles in 6 events and 14 other events were found, and the qualitative approach prevailed in more than half of those, and only six made use of an approach using a combination of qualitative and quantitative methods. By the authors was made a model demonstrating the networks formed between them, which makes it clear that knowledge is generated in groups that work together, but there is little circulation between the different groups, there is little interaction between researchers. Moreover, $80 \%$ of total production is in events, so the literature in this area has yet to solidify more nationally.

In the studies above, it becomes apparent that there is still room to develop further research to understand the publications in the area of organizational culture. Not only because it is a theme that permeates the entire organization, but also because the organizational culture is beyond the boundaries of organizations. Currently, among other ways to negotiate and 
maintain sustainable market, companies have sought to innovate with their partnerships, e.g. forming interorganizational networks, which creates a whole new cultural interaction, and according to the studies cited here, this is not a topic that is being on the spotlight or examined carefully.

Therefore, in order to complete and continue the path of these studies, the aim of this article is to make an analysis of published articles on organizational culture from 2008 to 2013 and understand the current situation of research on the topic.

\section{METHOD}

Seeking to provide some perspective on the current scenario in the theme, this study is characterized as a bibliometric study. According to Ramos-Rodriguez and Ruiz-Navarro (2004), the study of articles published in journals is considered as a recognized knowledge, as the articles have passed through the critical review by other researchers and were approved, and for that reason they are a good parameter for evaluating the knowledge base that is being developed in some issues.

In order to perform this research, the study was divided into two parts: the search for articles (in national and international journals) and the alignment and analysis of the data collected. First, searches were conducted in the database Scopus - which is the largest base of abstracts and references from peer-reviewed scientific literature (Scopus-Elsevier, s.n.) - looking for the keywords "organizational culture". After the filter, 1437 papers relating to these words were found. The results were exported to an Excel spreadsheet, where they were listed with the following information: author, title, journal, year of publication, major themes, keywords, method used in research and the university to which the authors belong.

Some articles were excluded, according to the criteria: articles that did not contain the relevant information for the analysis and articles that were not in journals in the areas of Administration, Psychology, Anthropology / Sociology; articles that were out of some of the terms of analysis and articles that contained no culture organizational in the title or in the keywords. The exclusions were 
made in order not to blur the proposed theme, ending with a total of 522 articles that were in accordance with the limits for inclusion in this research.

A further search was done for Brazilian scientific journals, looking for the keywords "cultura organizacional" exactly like that in Portuguese, with a total result of 31 articles that were in accordance with the limits of this work, as stated in the above paragraph. The English and Portuguese keywords were chosen based on the theme, as a way to maintain the results narrowed to the specific topic of the study.

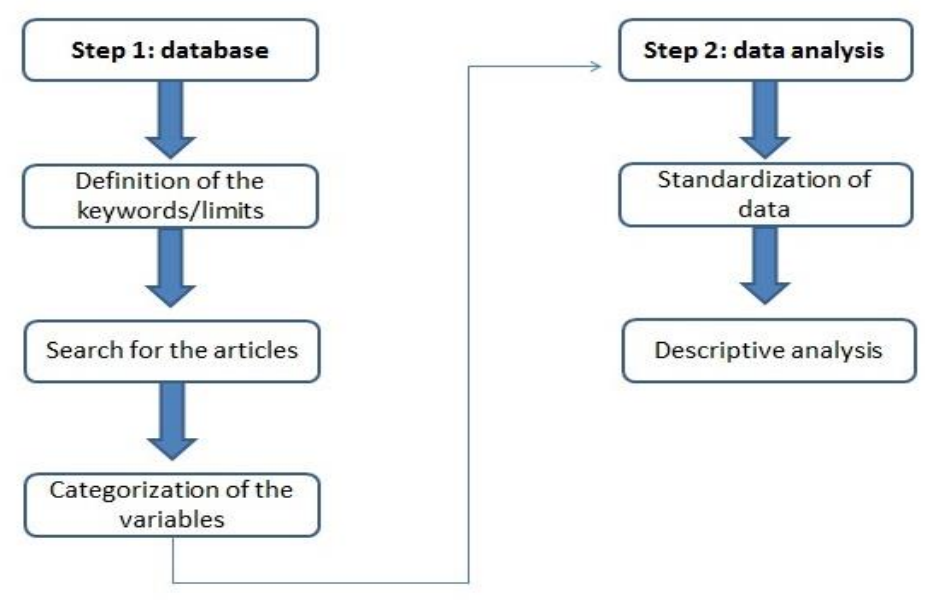

\section{Figure 2: Research design}

Source: Elaborated by the authors

The Brazilian and international articles were analyzed separately to keep the keywords as chosen by the authors, not losing anything for translations and also as a way to compare Brazilian publications with international ones.

After this initial phase, a quantitative research was carried out, using descriptive statistics (Hair et al., 2005), seeking to describe aspects of the sample found among the selected articles, counting the frequency of results that will be presented in the following section, as defined by the categories of research analysis that served to evaluate all items under the same scope, offering a wide view on the results of publications on the subject.

\begin{tabular}{c|c|c}
\hline \multicolumn{3}{c}{ Categories for analysis } \\
\hline Authors & Journal & Method \\
\hline Year & Theme/Keywords & University \\
\hline
\end{tabular}




\section{Table 1: Categories observed in the publications}

Source: Elaborated by the authors

These categories were chosen as a way to find some details on the theme, although they are not very deep in information they allow the research to use a larger number of articles. So, it is not possible to go deep into the subject of each article, but it is possible to create some panoramic view on the publishings about organizational culture. Thus, it may help some researchers to go to the right or faster path to find possible authors to read, the most commom method, the universities and journals that are usually more open to discuss the theme.

\section{DATA PRESENTATION AND ANALYSIS}

Summing all the articles there was a total of 553 publications, among national and international journals. There is a significant difference between national publications - with 31 articles - and international, with 522 articles analyzed. It is possible to imagine that this is due to the smaller number of Brazilian journals, besides that, Brazilian publications are still very restricted to Brazilian researchers probably due to the language, while other international journals often publish not only in their native language but also in English, opening the possibility of publishing for authors from several other places.

\section{a) Analysis per year of publications in journals}




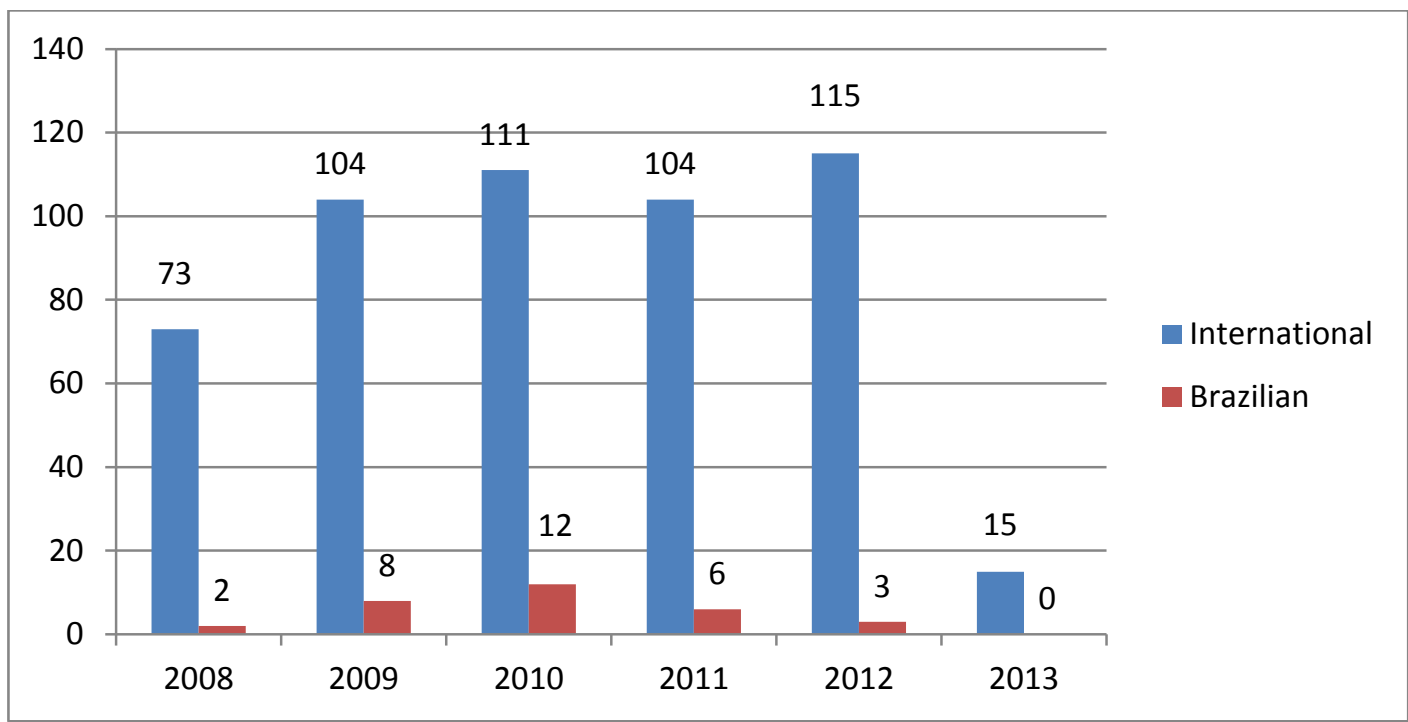

Graph 1: Publications per year

Source: Research data

First of all, it is necessary to state that the analyzes of 2013 are incomplete, because during the period of this research the year is in its first trimester, so many publications have not been disclosed yet.

With the analysis of the graph it can be seen that apart from the difference between the publications in international journals and Brazilian ones, there is also an average of publications in international journals, which has been maintaining itself for the last few years. However the same does not occur in Brazilian publications, where the average does not seem to keep up, it is uneven. This creates a contradiction, where publications in international studies about organizational culture seem to keep as a relevant topic for researchers and in Brazil they are not creating the necessary interest to develop local research and publications.

\section{b) Analysis of the keywords}

In any analysis of the articles, whether published in Brazilian journals or not, the occurrence of keywords "organizational culture" was the most frequent. And it is to be expected, coming from a bibliometric study that sought by this theme. 
Graph 2 shows visually the most repeated words between keywords indicating also the themes used to cross with organizational culture when performing a search.

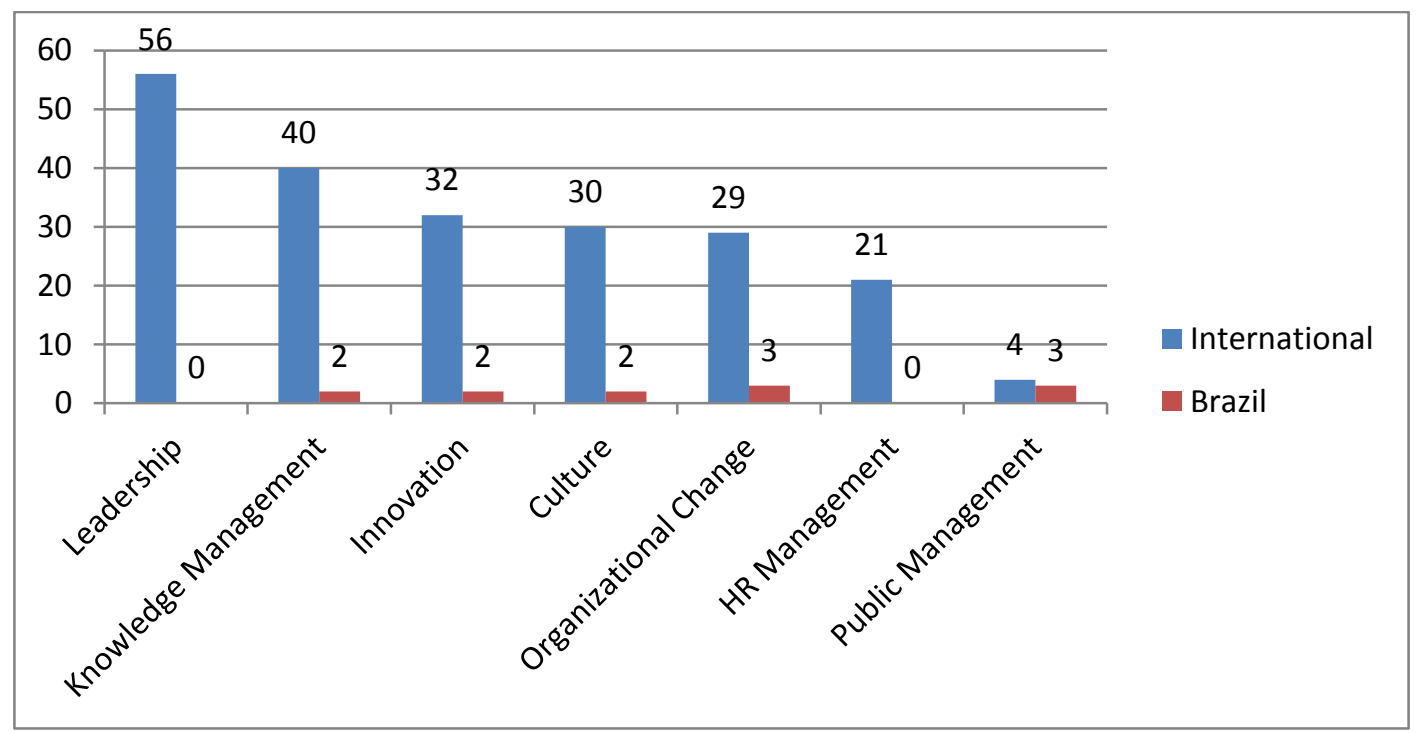

\section{Graph 2: The most used keywords}

Source: Research data

This graph demonstrates that the articles published in Brazil cover topics very similar to those published in international journals, except in a theme that was recurring with 3 appearances among Brazilian articles: public administration. According to the numbers, this theme does not seem to be relevant in international publications, demonstrating that in Brazil, probably due to the political configurations of the country, public and governmental issues are a matter of importance to the Administration area.

Back in Pereira, Passos and Carvalho (2010) some subjects were more associated with studies of organizational culture identified by the authors as organizational change, identity, commitment, learning, culture and public organizations. This shows that some topics remain linked with organizational culture studies published in Brazil and abroad.

\section{c) Journals with the greatest number of articles on the theme}

Some journals have a more prominent number of articles published on the subject over the years covered in this study. Journals in Brazil are more 
heterogeneous, also due to the small number of articles found, although there are a range of papers published on the subject, which demonstrates that the area has being recognized on its importance and the researches are welcome to publishing.

The Brazilian journals which were more eminent had only four publishings on the topic: Cadernos EBAPE.BR and Revista de Administração Mackenzie. In comparison, international journals had a greater number of journals variety and also of published articles in each one, as it is shown below.

\begin{tabular}{|c|c|}
\hline Journal & Quantity \\
\hline Journal of Organizational Change Management & 18 \\
\hline Leadership and Organization Development Journal & 17 \\
\hline International Journal of Human Resource Management & 14 \\
\hline Human Relations & 13 \\
\hline Quality - Access to Success & 13 \\
\hline Human Resource Management International Digest & 10 \\
\hline International Journal of Quality and Reliability Management & 10 \\
\hline Journal of Business Ethics & 10 \\
\hline
\end{tabular}

\section{Table 2: Journals with greater number of articles}

Source: Research data

Through the journals with the highest number of publications, it is possible to verify that from the 31 publications in Brazilian journals, about $25 \%$ of the analyzed publications focused on only two journals. Nevertheless, in the international side that have had at least 10 publications in the period studied, there are 8 different journals, with a total of 105 articles in these, representing an average of $20 \%$ of the total articles found.

It is outstanding the variety of articles and international journals that have published on the topic of organizational culture in recent years, demonstrating that the research in the area brings up interest for publications and that there is international field to promote research and disseminate knowledge that is being produced in academia.

\section{d) Authors, countries and universities}


Among the authors of the articles were analyzed the ones with more articles published, if they have stood up by the amount of studies, observing which countries and universities those authors have belonged or worked in.

In the articles published in Brazilian journals, it is possible to verify that two authors have 3 publishings each, being either the main author or in partnership with others and these are the authors with the highest number of publications. Again, the numbers in this case are low due to the low number of articles found by the Brazilian side of the search. These two authors are: one belonging to the Federal University of Rio Grande do Sul and the other to the Federal University of Pernambuco. Furthermore, most of the authors are linked to some Brazilian federal university in various parts of the country, indicating that the academic research is being carried out on these institutions in a greater number.

Articles in international journals have a different picture when it comes to the authors. Some of authors with more publishings during the study period had authored around five appearances. Relating these numbers to the total number of articles in each section, it is noticeable that the Brazilian authors tend to publish and search in a more concentrated area. While it seems that the authors from abroad are seeking for diversification, the results showing a remarkable quantity of articles, but different authors.

As for the country of the international journals selected, the authors were distributed in several countries, but few have had a more meaningful representation. In total, the authors were from more than 60 countries throughout the world, resulting in a variety of researches. Among the countries represented in greater numbers (more than 20 articles per country) there are: United States of America, United Kingdom, Australia, Canada, China, Spain and Taiwan.

And among the universities to which some of those authors belong to, some institutions have 5 authors, all the remaining others had fewer authors. Those most frequently cited were: Monash University, Macquarie University, University of Stavanger and Loughborough University.

In a certain way, the data demonstrates that studies of organizational culture are everywhere and have very different authors, then probably having 
multiple focus and directions. This sustains the view that organizational culture generates a very different approach in the concept, methodology and objectives adopted by the researches, and generate impacts so assorted (Coelho Junior, 2003).

\section{e) About the methods used in the articles}

The result referring to the method was based on the authors' own definitions: the method was sought between two categories - qualitative and / or quantitative - in the summaries of articles, due to the impossibility to read that many articles to find this information. The first record is that many authors do not state a clear methodology definition in the abstract. In order to have a reliable result, it was recorded as method only if it was clearly written, it was not defined according to the nomenclature of the methods, since many are hybrids and only the summary was not clear about which of the two options was applied in that study.

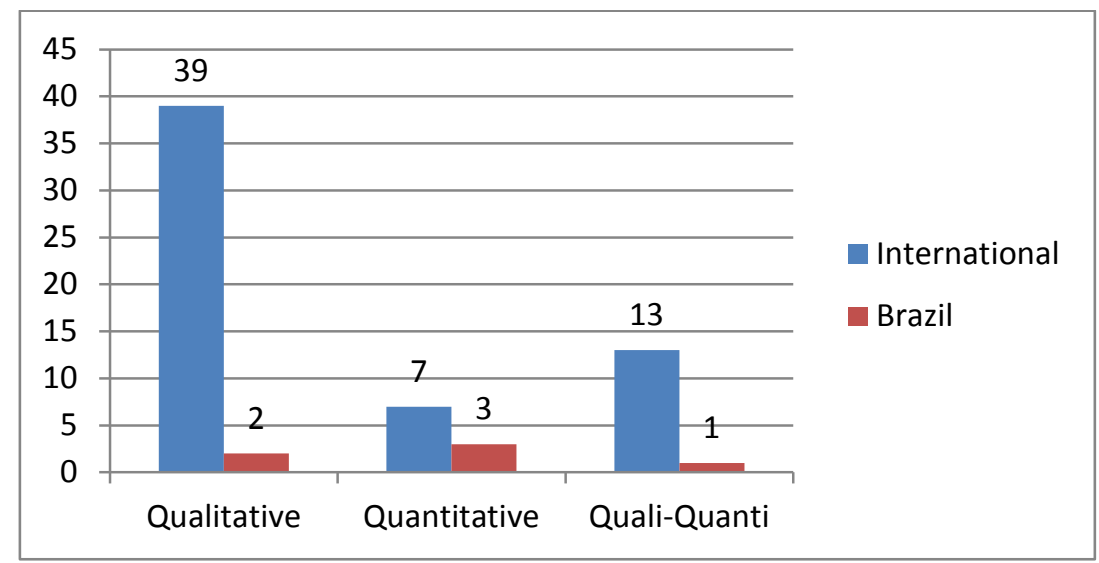

\section{Graph 3: Methodology in the articles}

Source: Research data

Although the numbers are not sufficient to state something strongly, it can be seen that there is a predominance of qualitative studies and some international studies seek to connect the two methodologies, qualitative and quantitative, doing research that can bring broader and more fruitful results.

\section{FINAL CONSIDERATIONS}


This study has sought to identify a profile of the publications on the area of Administration and other similar areas, on organizational culture. Articles were analyzed separately: articles found in international databases and other published in journals available in Brazil.

Some studies that dealt with organizational culture, resulting in bibliometric research were also cited, showing that there is still room to understand what is being done in the area, looking for ways to understand what paths researches have followed and how to improve the performance of future investigations.

According to Plakhotnik and Rocco (2006) most authors define organizational culture as a phenomenon spread throughout the organization, which impacts on workers productivity and effectiveness of services. It is a process that delineates the character of the organization and assists in defining roles, goals, plans.

The journals analyzed here were chosen through a database of international journals (Scopus) and through the search for Brazilian journals. Within the search, 522 articles were found in international databases and 31 in Brazilian journals that were in accordance with the limits of this research. The articles were published between the years 2008 and 2013 (first quarter for the latter), and were chosen for containing in the keywords or title the expression "organizational culture". They should also contain the information necessary for the analysis - such as author names, complete summary available, published in journal in the field of Administration, Psychology, Social Sciences and similar areas.

After the results of this study, it can be said that there is a big difference between the number of papers published internationally and in Brazil. There is still room for research in Brazil to strengthen itself and for the journals to have more articles on the subject. Even so, the subject organizational culture seems to be well accepted, having a large penetration in organizations, being connected with several other topics, providing significant investigations with different focuses.

Mainly by the international numbers, it is possible to say that the subject has been growing, with more and more publications, expanding the possibilities 
for researchers to carry out studies in this area and share the knowledge with the academic community. This is verified by the fact that over the years the numbers of articles in the area have been increasing, with a total of 75 articles in 2008; 202 in 2009; 123 in 2010; 110 in 2011; and 118 in 2012; and 15 in 2013 until the moment of this research. Even though the latter is at the beginning of the year, it could mean that there is space for an increasing in the number of publications as periodicals are launching their issues.

Some journals have appeared more often, working the theme of the area, especially in the area of management as: Cadernos EBAPE.BR and Revista de Administração Mackenzie, Journal of Organizational Change Management and Leadership and Organization Development Journal. They also indicate the presence of few themes worked in the field, both nationally and internationally, as change in organizational culture, leadership, knowledge management, and others.

However, some issues have been little worked when talking about organizational culture: interorganizational culture; education culture; culture in nonprofit organizations, among others, had little or no appearance among the keywords of the articles. These facts highlight that there is not only room for studies on organizational culture, but also space for studies underdeveloped, with innovative themes linked to the main subject.

The authors of these articles are quite diverse, it is not possible to say that there is a concentration at this moment, although some countries have more researchers involved with the theme, as United States, United Kingdom, Australia, Canada, China, Spain and Taiwan. Also, the preferred method research has been the qualitative approach. Though, it is important to highlight the fact that there are 14 articles with a mixture of qualitative and quantitative research, which shows that researchers seek for more complete and complex ways to understand the subject of organizational culture in academic researches which are being carried out.

This research was limited to analyzing only a few factors, highlighting the difference between Brazilian publications and in international journals. It is suggested that further research on the topic is a great opportunity to broaden the perspective on the methods used, also thinking about the most cited 
bibliographies, the networks formed among the authors in the area and the communication between them.

Furthermore, it is important to highlight the fact that widening the database for further research is a great opportunity to deepen the knowledge on the subject and better understand the publications on the area, overcoming some of the limits, which are part of every research.

\section{REFERENCES}

Alvesson, M. (2002). Understanding organizational culture. Thousand Oaks, CA: Sage.

Coelho Junior, F. A. (2003, janeiro/junho). Gestão estratégica: um estudo de caso da percepção de mudança de cultura organizacional. Psico - USF, 8(1), 81-89.

Coelho Junior; F. A. \& Borges-Andrade, J. E. (2004, julho/dezembro). Percepção de cultura organizacional: uma análise empírica da produção científica brasileira. Psico -USF, 9(2), 191-199.

Engman, L. \& Thörnlund, N. (2008). The influence of international franchising on corporate culture. Bachelor thesis, Luleå University of Technology, Sweden.

Fuhse, J. \& Mützel, S. (2011). Talking connections, structure and meaning in networks: quantitative and qualitative methods in sociological network research. Quality \& Quantity, 45(5), 1067-1089.

Hair, J. et al (2005). Análise multivariada de dados (5a ed.). Porto Alegre: Bookman.

Heinzmann, L. M., Machado, D. D. P. N. \& Ropelato, M. (2010). Cultura organizacional: redes formadas na literatura nacional. Encontro de Estudos Organizacionais da Anpad, 6, Florianópolis, SC, Brasil.

Hofstede, G. (2001). Cultura e organizações: compreender a nossa programação mental. Lisboa: Edições Sílabo.

Motta, P. R. (1998). Transformação organizacional: a teoria e a prática de inovar. Rio de Janeiro: Qualitymark.

Motta, F. C. P. \& Vasconcelos, I. F. G. (2004). Teoria geral da administração. São Paulo: Pioneira Thomson Learning. 
Plakhotnik, M. S. \& Rocco, T. S. (2006). Organizational culture: a literature review of the AHRD 1994-2005 proceedings. In M. S. Plakhotnik \& M. Nielsen (Eds.), Proceedings of the Fifth Annual College of Educational Research Conference: Urban and International Education Section (pp. 9499). Miami: Florida International University.

Pereira, V. S., Passos, J. C. \& Carvalho, C. (2010). Cultura o quê? Um estudo bibliométrico da produção científica brasileira em Administração sobre cultura organizacional da última década (1998-2009). Anais do Simpósio de Administração da Produção Logística e Operações Internacionais, 13, São Paulo, SP, Brasil.

Ramos-Rodriguez, A. R.; Ruiz-Navarro, J. R. (2004). Changes in the intellectual structure of strategic management research: a bibliometric study of the Strategic Management Journal, 1980-2000. Strategic Management Journal, 25(10), 981-1004.

Schein, E. H. (2004). Organizational culture and leadership (2nd ed.). San Francisco, CA: Jossey-Bass.

Scopus-Elsevier. (s.n.). Available online: <http://www.scopus.com>. Access: March, 2012.

Silva, L. P. \& Fadul, E. (2010). A produção científica sobre cultura organizacional em organizações públicas no período de 1997 a 2007: um convite à reflexão. Revista de Administração Contemporânea, Curitiba, 14(4), 651-669.

Vieira, A. C. G. \& Fischer, A. L. (2005). Análise da produção científica em clima, cultura e remuneração e salários entre 1999-2004. Anais do Seminários em Administração, 8, São Paulo, SP, Brasil.

Vieira, A. (2010, janeiro/junho). Cultura, poder e identidade nas organizações. Revista de Administração da FEAD - Minas, 1(1), 61-75. 